\title{
PLANT HEALTH PROTOCOLS FOR THE REINTRODUCTION OF NATIVE PLANTS
}

\author{
Natacha Frachon ${ }^{1}$
}

\begin{abstract}
Many botanic gardens and conservation agencies are now cultivating threatened native species specifically for reintroduction programmes in response to the second part of Target 8 of the Global Strategy for Plant Conservation (GSPC). While collection, cultivation and reintroduction techniques are frequently discussed in workshops and described in papers, few seem to have considered the threats of introducing non-native pests, diseases, weeds and hybrids between different populations of the same species. The Royal Botanic Garden Edinburgh has been cultivating plants for its Target 8 programme since 2005 and now grows 82 per cent threatened Scottish species. It is running active reintroduction programmes for nine of these species with programmes planned for a further five species. In recent years increasing attention has been paid to reducing the risks of introducing non-native organisms and hybrids between different populations of native species into the wild. This paper describes the protocols that have been developed, including verification, screening for pests and diseases, averting spontaneous hybridisation and preparing plants for reintroduction.
\end{abstract}

\section{INTRODUCTION}

From the start of the Target 8 Project of the Global Strategy for Plant Conservation (GSPC) in 2005 (Frachon et al., 2005), the Royal Botanic Garden Edinburgh (RBGE) became actively engaged in the conservation of some of Scotland's rarest plant species (McHaffie et al., 2011). Our actions are undertaken within a broad and rigorous framework encompassing field surveys, collecting from the wild, offsite propagation, plant recovery programmes and subsequent monitoring. Most of the conservation collection of Scottish native plants is held in a shade tunnel in the RBGE Nursery. Other facilities are used when needed during the early stages of propagation.

Maintaining plant propagules in optimal conditions is crucial for the success of their reintroduction into native communities. The risks associated with propagating plants destined for reintroduction away from the site of the original population are particularly prevalent in botanic gardens where a great diversity of species are being grown in close proximity. Risks include the possibility of introducing non-native pests, diseases, weeds and foreign genotypes resulting from spontaneous hybridisation. All of these can be associated with the relocated species as soil contaminants and carry the potential to cause tremendous harm to indigenous habitats and ultimately undermine ex situ conservation efforts. Thus, the grower's duty of care must include anticipating the potential for

1. Natacha Frachon is a Horticulturist at the Royal Botanic Garden Edinburgh. Address: 20A, Inverleith Row, Edinburgh, EH6 5LR.

Email: N.Frachon@rbge.org.uk 


\section{RBGE Horticulture Division}

Royal

Botanic Garden

Edinburgh

20A Inverleith Row

Edinburgh EH3 5LR

Scotland, UK

\section{Plant Health Assessment as a biosecurity tool to evaluate plants for reintroduction}

Tel $+44(0) 1312482800$

Fax $+44(0) 1312482928$

Web uww.rbge.org.uk

Risk Assessment of: stock of Salix myrsinifolia propagated off site

Date: $20^{\text {th }}$ August 2012

Destination of plant material: Corrie Sharroch

Reason: Reinforcement programme

Plant Collection Summary: 5 accessions of 4-years-old plants of Salix myrsinifolia grown from wildcollected seed from Corrie Sharroch

\section{Pathogens and Predators Assessment}

- Estimate the \% of rust severity and herbivore damage extent using the scores below.

\begin{tabular}{|l|l|c|l|c|}
\hline \multicolumn{1}{|c|}{ Taxon } & \multicolumn{1}{|c|}{$\begin{array}{c}\text { RBGE } \\
\text { accession } \\
\text { number }\end{array}$} & $\begin{array}{c}\text { Number of } \\
\text { plants }\end{array}$ & \multicolumn{1}{|c|}{ Rust score } & $\begin{array}{c}\text { Herbivore damage } \\
\text { score }\end{array}$ \\
\hline Salix myrsinifolia & 20080808 & 49 & $\begin{array}{c}5-6 \text {-all plants have at least 1 } \\
\text { pustule on 1 to 10 leaves. }\end{array}$ & 1 \\
\hline Salix myrsinifolia & 20080809 & 19 & $\begin{array}{l}5-6 \text {-all plants have at least 1 } \\
\text { pustule on 1 to 10 leaves. }\end{array}$ & 1 \\
\hline Salix myrsinifolia & 20080810 & 79 & $\begin{array}{l}5-6 \text {-all plants have at least 1 } \\
\text { pustule on 1 to 10 leaves. }\end{array}$ & 1 \\
\hline Salix myrsinifolia & 20080811 & 33 & $\begin{array}{l}5-6 \text {-all plants have at least 1 } \\
\text { pustule on 1 to 10 leaves. }\end{array}$ & 1 \\
\hline Salix myrsinifolia & 20080814 & 27 & $\begin{array}{l}5-6 \text {-all plants have at least 1 } \\
\text { pustule on 1 to 10 leaves. }\end{array}$ & 1 \\
\hline
\end{tabular}

Rust severity score

$1-3$ leaves with one pustule per leaf

1-3 leaves with more than one pustule per leaf OR more than 3 leaves with one pustule per leaf (less than $25 \%$ of all leaves infected)

3 More than 3 leaves with several pustules each (less than $25 \%$ of all leaves infected)

$425 \%$ of all leaves with pustules, many with more than 1 pustule

$50 \%$ of all leaves with pustules, many with more than 1 pustule

$50 \%$ of all leaves with pustules, most with more than 1 pustule, many with many pustules

$75 \%$ of all leaves with pustules, many with more than 1 pustule

$75 \%$ of all leaves with pustules, most with more than 1 pustule, many with many pustules

9 All leaves with pustules, most with more than 1 pustule, many with many pustules

10 All leaves with pustules, all with many pustules

from Milne et al. 2012

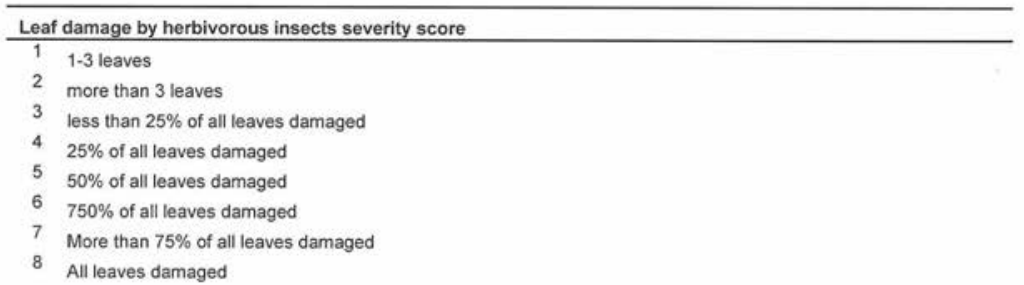

Fig. 1 Plant Health Certificate. Photo: Natacha Frachon. 
- Were any other pest and disease detected?

Leatherjacket grubs, Caterpillar, codling moth were handpicked when found.

Prior to packing each plant were inspected from top to bottom in search of egg capsules.

Occasionally, land snail egg masses were found and removed.

No flatworm egg capsules were seen.

No vine weevil larvae found.

- What were the methods of pest and disease control?

Non chemical alternative were used against pest and disease, except at germination stage, when a solution of Cheshunt Compound was applied to prevent damping off.

Biological control using the nematodes (Steinernema kraussei) Nemasys $\circledast$ L has been applied annually to prevent vine weevil infestation. From 2008 the willow stock has been treated twice a year once mid-spring, once early September. Date of last treatment with Nemasys $\otimes H-26^{\text {th }}$ June 2012.

\section{Weed Assessment}

- If any, which types of weed were found colonising the containers?

Liverworts, moss, gelatinous algae on the surface of compost. Very occasionally seedlings of Cardamine sp, and Epilobium sp. were found.

- What were the methods of weed control?

At all times, weeds were uprooted and no chemical was used to control weeds.

\section{Hybridisation Prevention}

- Is the stock vegetative?

Each plant has been subjected to a meticulous inspection for the presence of ripe and/or unripe catkins. Fruits were removed when seen.

- Date of last inspection for catkins?

$20^{\text {th }}$ August 2012

\section{Collection Maintenance}

- What is the media used for growing the stock?

Melcourt peat free Sylvamix

- Has any fertilisers being used to grow the stock?

No fertilisers have been added in the potting mix. However, starting from April, the plants received a weekly liquid feeding regime of Sangral 3:1:3 (solution dilution 1:100). The feeding was stopped one month prior to reintroduction.

\section{Collection Identification}

- Has the plants' name been confirmed?

Individuals of each accession have undergone a secondary taxonomic determination.

- How many plants were incorrectly named?

All plants were correctly named.

\section{Additional comments}

Scorched leaf tips on several plants probably due to a day of low humidity and gusty winds

Inspected by: Stephan Helfer, Senior Mycologist and Natacha Frachon, Horticulture.

Signature: 


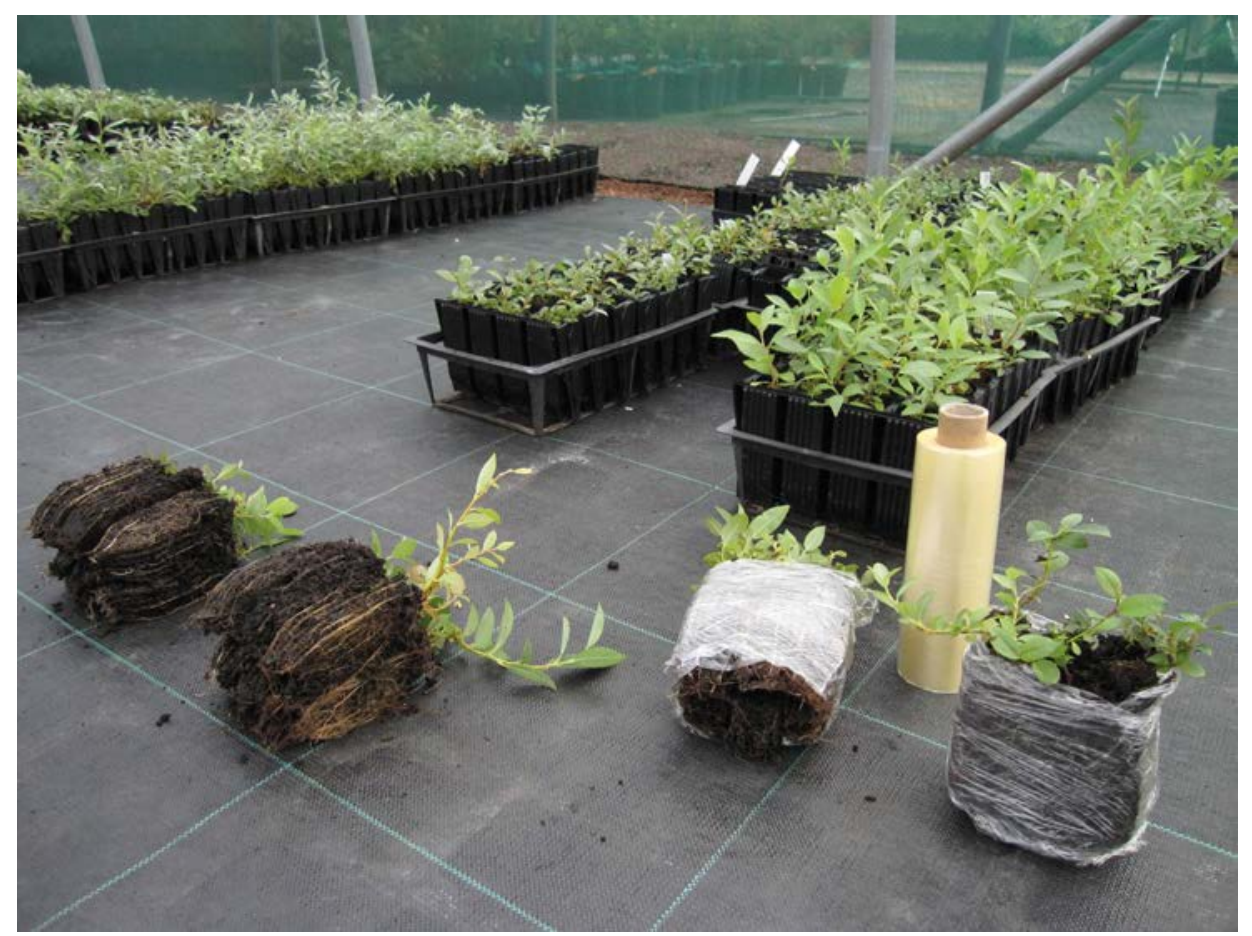

Fig. 2 Willows ready for packing. Photo: Natacha Frachon.

unintended outcomes and the prevention of any threats likely to occur from propagation until planting.

The 2011 outbreak of Phytophthora austrocedrae in Cumbria, which originated from reintroduced Juniperus communis (juniper) using ex situ-grown transplants, provided an incentive to RBGE to develop a risk assessment system aimed specifically at plant reintroduction. ${ }^{2}$ Actions involve inspecting the health of individual plants, photographing them and completing a checksheet. The purpose of the inspection is to ensure that only high-quality stock plants are utilised for reintroduction. Additionally, the checksheet retains the cultivation history of the plants for future reference (Fig. 1). This paper reviews our recently established practice of ex situ conservation with particular emphasis on the maintenance of ex situ conservation collections destined specifically for in situ reintroduction.

The day before leaving the RBGE Nursery, plants are removed from their containers and packed for transportation (Fig. 2). This is a critical time when final monitoring and careful inspection of individual plants can be carried out. It involves verifying the identity of the plants, searching for pests, diseases and weeds, and removing fruiting material. These steps are very important and each merits consideration:

2. Upper Teesdale National Nature Reserve in Cumbria and County Durham. 


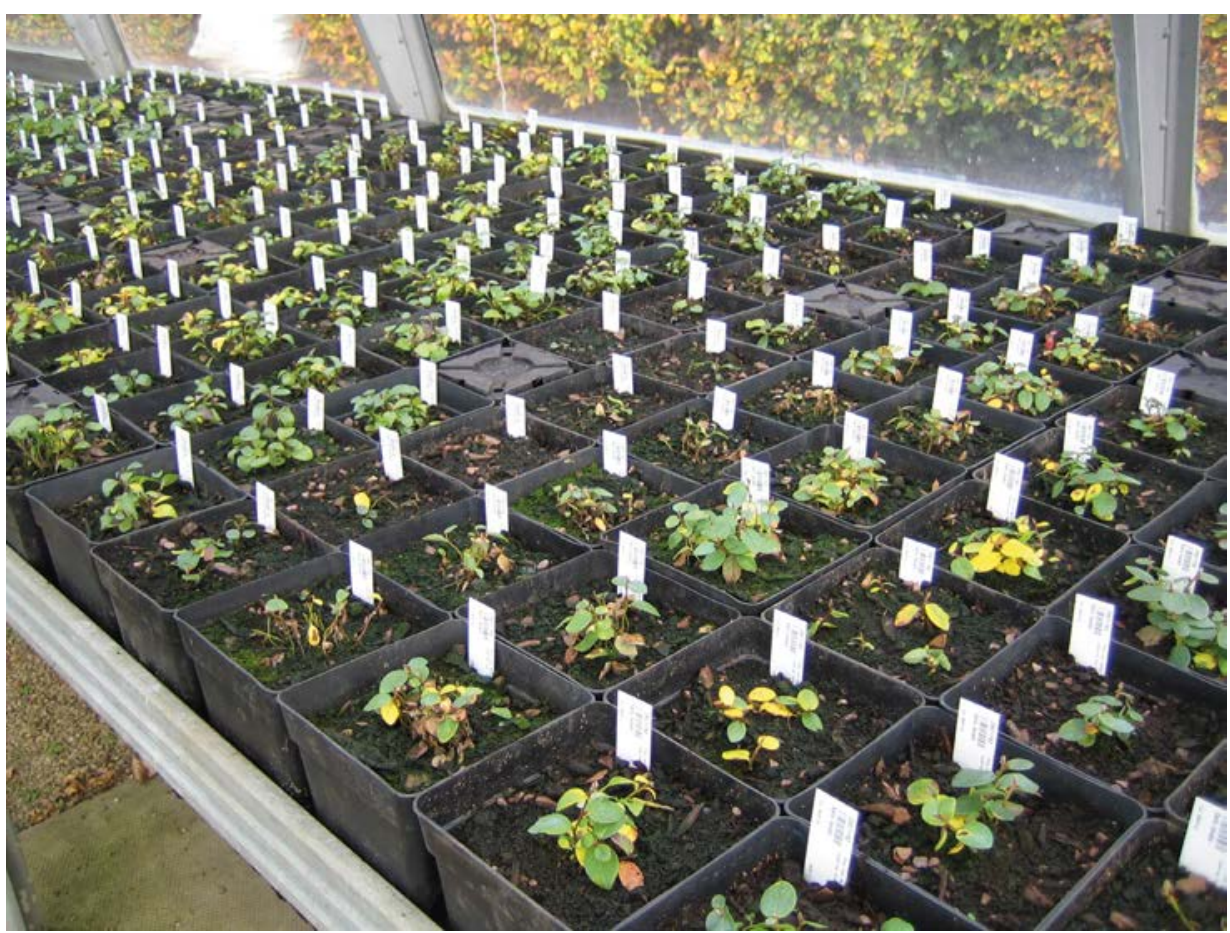

Fig. 3 Rows of labelled pots. Photo: Natacha Frachon.

\section{Verification $^{3}$}

All acquisitions of new plant material for ex situ conservation are wild-collected and received with a scientific name and full collection data. When the material enters the RBGE Living Collection it is labelled with a unique accession number which links the plant to its identification record.

The loss of the correct label, mislabelling or accidental mixing of labels can happen when plants are being moved from one place to another. Labels may also be dislodged or broken due to the rigours of the Scottish weather. To prevent this from happening all plants are individually labelled with plastic tags containing the accession information and these are carefully and securely attached to the plant or to their container. This entails a small cost in terms of time, effort and expense yet it is a worthwhile investment because a plant that has lost its identification is no use for conservation and will be discarded (Fig. 3).

Individual plants of each accession undergo a secondary identification to confirm their existing name. This verification process is of prime importance to ensure that we

3. Verification is defined as "the process of identifying and accurately naming plants. This may involve the confirmation of an existing name, the changing of an existing name to another name or the determination of the plant's identity." (Rae et al., 2012) 
are supplying the correct taxa for reintroduction. On a very few occasions, for instance, we have found 'lookalike' plants growing among our conservation collection of willows. At some stage they had outcompeted the cultivated plants unseen, until they were found and removed in the course of this last identification. Finally, plant names may change because of taxonomic reclassification and it is good practice to adopt the most up-to-date taxonomic treatments.

\section{Screening plants for pests and diseases}

The RBGE Nursery grows wild origin, and therefore imported, plant material from all parts of the world. Despite having our own dedicated and licensed quarantine facilities, this is a potential entry point for non-indigenous pests, weeds and diseases. Cardamine corymbosa, commonly known as New Zealand bittercress, is now, for instance, a wellestablished weed in the Nursery. Although there is no record of it being invasive in Scotland's natural habitats we remain cautious and so it is removed as soon as it is seen, as are any weeds found growing in the conservation plant collections and in the adjacent premises.

The dissemination of alien pests or diseases from cultivation into natural communities is an additional risk. Non-native flatworms such as the 'New Zealand' flatworm (Artioposthia triangulata) and its smaller 'Australian' cousin (Caenoplana alba) prey on native earthworms and are becoming widespread in the UK with several occurrence records in Scotland (Scottish Natural Heritage, no date). The New Zealand flatworm is present in the RBGE Nursery. It lays egg capsules which can rest for a long time between the root ball and the edge of the container. Potted plants are therefore checked regularly and egg-laying or soil-born grubs are destroyed when found.

As far as possible, we have opted for an ecologically based approach to managing the conservation collection of Scottish plants. The reasons for this approach are that pesticide and herbicide resistance are problems with which growers have to contend. Moreover, the chemical control of pests and weeds is costly, damages the wider environment and may impact on the vigour and fertility of the plants intended for reintroduction. Physical hand-weeding is preferred and when it becomes part of routine maintenance, it is truly not a time-consuming chore. Likewise, codling moths, caterpillars and other leaf-eating grubs are handpicked and biological control such as nematodes is used to prevent vine weevil infestation. Finally, maintaining good hygiene of the premises and all equipment is the basic and most effective method of preventing diseases and contamination between plants.

\section{Averting spontaneous hybridisation}

A large number of plants grown in our conservation collection are either closely related species or the same species but originating from different populations. They are grown in close proximity, their flowering time often overlaps and they share the same 
pollinators within the facility. This allows random cross-pollination to occur and may result in new hybrids. An integral part of ex situ conservation is to preserve the species' genetic diversity and integrity. Moreover, offspring of cross-pollination in cultivation may become invasive if released in nature which could compromise the survival of wild populations. Our responsibility is to ensure that measures are taken to prevent or minimise the potential for open pollination. Because of a lack of space in the ex situ facility it is not always possible to isolate crossable species. As soon as the growing season begins we inspect the collection, deadhead flowers and remove any unripe fruits or catkins. In effect, no seedheads are left to release seeds. It is important that this is carried out on a regular basis during the growing season as deadheading speeds up the formation of new flowers. Finally, the day prior to reintroduction we double check that all plants have no flowers and that no seeds lie on the growing media.

\section{Preparing plants for reintroduction}

One of the challenges of growing plants for restoration projects is to ensure that they don't become 'dependent' on cultivation, meaning that they thrive when given constant attention but can't grow successfully in wild conditions. Dependence on cultivation may compromise their fitness to survive in the wild. The goal of conventional cultivation is to provide ideal growing conditions for the plants, meaning the adequate quantity of water and nutrients, the right amount of light and shade, protection from pests and diseases and the absence of grazing predators and plant competition. Those involved in ex situ cultivation have the further responsibility of preparing the plants for the environmental pressures that await them once reintroduced. This entails maintaining a reasonable balance between supplying the optimal growing conditions and minimising the dependence on cultivation.

In our Scottish plant conservation collection, plants are grown in peat-free media and we do not use components that are non-native such as coir or perlite. ${ }^{4}$ Fertiliser is not added to the potting mixes but plants receive a weekly liquid feed from the start of the growing season. ${ }^{5}$ While most plants can tolerate high levels of fertiliser, we stop feeding one month prior to reintroduction to harden off the future transplants. As far as possible, we simulate the natural growing conditions of the species. Once the plants have germinated in an outdoor seed frame they are moved into a shade house. However, where more specialised environments are necessary for vegetative propagation, such as fog units and mist benches, the rooted plants are weaned off these conditions for as short a time as possible. The propagules are then transferred to the shade tunnel where they become acclimatised to outdoor conditions.

The great advantage in carrying out ex situ conservation for species that are native to Scotland is that plants are grown in the climate that suits their cultural needs. Overall

4. Melcourt Sylvamix ${ }^{\circledR}$ growing media customised mixes.

5. $1 \%$ Sangral N/P/K 3:1:1. 
it is a cost-effective operation: their cultivation requires a minimum of maintenance and, with very few exceptions, there is no need for any 'high tech' growing environments. More importantly, it mitigates the transition of plants from cultivation to the habitats where they belong.

We continue to learn as our conservation programmes develop and there is still more to gain from observation and experimentation. Exchange of new ideas and alternative strategies between all the organisations involved in ex situ conservation is essential to build on knowledge and good practice.

\section{ACKNOWLEDGEMENTS}

Thank you to Peter Brownless (Nursery Supervisor) and Stephan Helfer (RBGE Plant Pathologist) for their advice and support.

\section{REFERENCES}

FRACHON, N., JEBB, M. \& RAE, D. (2005). PlantNetwork's Target 8 Project - the survey stages, Sibbaldia, 3, 67-82.

MCHAFFIE, H., FRACHON, N. \& ROBERTSON, A. (2011). Starting a conservation collection of Sorbus pseudomeinichii - the Catacol whitebeam. Sibbaldia, 9, 171-178.

RAE, D., CUBEY, R., HUGHES, K., GARDNER, M., THOMPSON, H., INCHES, F. \& KNOTT, D. (2012). Catalogue of Plants 2012. Royal Botanic Garden Edinburgh.

SCOTTISH NATURAL HERITAGE (2002). New Zealand and Australian flatworms in Scotland. Available online: www.snh.org.uk/publications/on-line/advisorynotes/7/7.htm (accessed August 2013). 